\title{
The PROCESS Experiment: Amino and Carboxylic Acids Under Mars-Like Surface UV Radiation Conditions in Low-Earth Orbit
}

\author{
Audrey Noblet, Fabien Stalport, Yuan Yong Guan,, Olivier Poch,, Patrice Coll, Cyril Szopa,2 \\ Mégane Cloix, Frédérique Macari, ${ }^{1}$ Francois Raulin,, Didier Chaput, ${ }^{3}$ and Hervé Cottin ${ }^{1}$
}

\begin{abstract}
The search for organic molecules at the surface of Mars is a top priority of the next Mars exploration space missions: Mars Science Laboratory (NASA) and ExoMars (ESA). The detection of organic matter could provide information about the presence of a prebiotic chemistry or even biological activity on this planet. Therefore, a key step in interpretation of future data collected by these missions is to understand the preservation of organic matter in the martian environment. Several laboratory experiments have been devoted to quantifying and qualifying the evolution of organic molecules under simulated environmental conditions of Mars. However, these laboratory simulations are limited, and one major constraint is the reproduction of the UV spectrum that reaches the surface of Mars. As part of the PROCESS experiment of the European EXPOSE-E mission on board the International Space Station, a study was performed on the photodegradation of organics under filtered extraterrestrial solar electromagnetic radiation that mimics Mars-like surface UV radiation conditions. Glycine, serine, phthalic acid, phthalic acid in the presence of a mineral phase, and mellitic acid were exposed to these conditions for 1.5 years, and their evolution was determined by Fourier transform infrared spectroscopy after their retrieval. The results were compared with data from laboratory experiments. A 1.5-year exposure to Marslike surface UV radiation conditions in space resulted in complete degradation of the organic compounds. Halflives between 50 and $150 \mathrm{~h}$ for martian surface conditions were calculated from both laboratory and low-Earth orbit experiments. The results highlight that none of those organics are stable under low-Earth orbit solar UV radiation conditions. Key Words: Mars-Astrobiology-Organic matter-Low-Earth orbit-UV radiationEXPOSE. Astrobiology 12, 436-444.
\end{abstract}

\section{Introduction}

$S^{\mathrm{n}}$ NCE THE FIRST orbital observations of the surface of Mars by the Mariner 4 probe, evidence of the past presence of large expanses of liquid water at the surface of the planet have been discovered (Mangold et al., 2004; Squyres et al., 2004; Poulet et al., 2005; Carter et al., 2010). Some observations suggest that liquid water (a supposed key condition for prebiotic chemistry and the emergence of life) was stable and widespread at the surface of Mars during the first 500 million years of the planet's history (Bibring et al., 2006). As a consequence, Mars is today an object of primary interest for astrobiology in that indications of a prebiotic chemistry, or even biological activity, could be found on the planet. Moreover, about half the surface of the planet is older than 3.8 billion years because of the absence of global plate tectonics. Therefore, past mineral or organic records of prebiotic chemistry or biological activity could be preserved, and their detection is one of the major objectives of the current Mars Exploration Program (Arvidson, 2000; Morrison, 2001; Hoehler and Westall, 2010).

The search for organic molecules at the surface of Mars started in the 1970s. The in situ Viking exploration mission reached the surface of the planet with instruments devoted to the detection of extant biological activity and the search for organic matter in regolith samples. However, no organic matter and no biological activity were unambiguously detected with the Viking instrumentation (Biemann, 1979). At

\footnotetext{
${ }^{1}$ Laboratoire Interuniversitaire des Systèmes Atmosphériques (LISA), UMR CNRS 7583, Université Paris Est Créteil et Université Paris Diderot, Institut Pierre Simon Laplace, Créteil, France.

${ }^{2}$ UPMC Université Paris 06, Université de Versailles Saint-Quentin, CNRS/INSU, LATMOS-IPSL, Paris, France.

${ }^{3}$ Centre National d'Études Spatiales, Toulouse, France.
} 
that time, the nondetection of organic molecules was considered surprising, even in light of the fact that it is possible that endogenous organic compounds present on Mars for millions of years are not detectable due to burial and degradation processes. Indeed, the interplanetary medium is still an active exogenous source of organic matter (Cottin et al., 1999; Botta and Bada, 2002; Elsila et al., 2009; SchmittKopplin et al., 2010), and if follows that this exogenous organic matter should have been detected by the Viking instruments. Today, two main hypotheses attempt to explain the Viking results: (i) the gas chromatograph-mass spectrometer (GC-MS) instrument would not have been ideally suited to detect low levels of organics in the samples collected by Viking (Navarro-González et al., 2006, 2010) and (ii) organics were effectively absent from the samples collected because of chemical processes that occur at the surface of the planet and lead to the degradation of these molecules (Stoker and Bullock, 1997; Benner et al., 2000; Ten Kate et al., 2006; Stalport et al., 2009, 2010a). Furthermore, it is also important to note that the Viking landers sampled martian soils from two very localized locations. After 40 years, debate with regard to results of the Viking mission is ongoing. The search for organic matter at the surface of Mars, however, began anew with the Mars Science Laboratory 2011 (NASA) and the ExoMars 2018 (ESA) missions. On board these two space probes instruments such as Sample Analysis at Mars (SAM) have the capacity to detect very low levels of organics (Cabane et al., 2004). Also, a new set of laboratory studies, developed within the Mars Organic Molecules Irradiation and Evolution (MOMIE) program, that support these ambitious space programs is devoted to evaluation of the behavior of organic compounds under simulated martian surface environmental conditions (Stalport et al., 2008, 2009, 2010a). The major goals of these studies are (i) the identification of the nature of organic molecules that could be stable or metastable at the surface of Mars, (ii) the assessment of the ability to detect them by in situ instrumentation, and (iii) the quantification of their abundance at the surface of the planet.

An assessment of the current martian surface environmental conditions reveals that several processes could be involved in the evolution of organic matter. Among these processes, UV radiation can be particularly efficient. Numerical models predict that the surface of Mars is exposed to an energetic UV flux in the 190-400 nm range (Kuhn and Atreya, 1979; Cockell et al., 2000; Patel et al., 2002). Laboratory experiments have been developed to mimic such radiation conditions and evaluate their impact on organic materials likely to be present at the martian surface (Stoker and Bullock, 1997; Gontareva, 2005; Ten Kate et al., 2005, 2006, Stalport et al., 2008, 2009; Shkrob et al., 2010). Those studies highlighted the degradation of most of the organic molecules. However, it is currently impossible to faithfully simulate the solar UV spectrum and flux in standard laboratory conditions. A good reproducibility of this parameter is very important in order to estimate the kinetic constants (lifetime, photolysis rate constant) for each organic compound. These kinetic constants are themselves essential to model the concentration of organic matter on Mars as a function of the depth, latitude, longitude, geological period, and so on. Therefore, we developed complementary experiments to support laboratory experiments and allow the exposure of samples to the solar spectrum in low-Earth orbit (LEO). This work has been initiated with the UVolution experiment. This experiment was contained in an ESA Biopan facility outside a Foton automated capsule in 2007 (Guan et al., 2010; Stalport et al., 2010a, 2010b). Another similar LEO study that is the topic of this paper, the PROCESS experiment, was part of ESA's EXPOSE-E mission and was installed outside the European Columbus module of the International Space Station (ISS) from February 2008 to August 2009. This experiment was led by the Laboratoire Interuniversitaire des Systèmes Atmosphériques; the Laboratoire Atmosphères, Milieux, Observations Spatiales; and the Centre de Biophysique Moléculaire; and it was supported by the European and French space agencies (ESA and CNES). The PROCESS samples consist of a set of organic compounds related to cometary or martian environments. This article presents the impact of UV radiation on these organic molecules.

\section{Materials and Methods}

The PROCESS experiment was part of the science payload of the European EXPOSE-E exposure facility (Fig. 1), which was attached to the outside balcony of ESA's Columbus module of the ISS for 1.5 years (Rabbow et al., 2012). A detailed description of the whole PROCESS experiment and its accommodation in the EXPOSE-E facility is given by Cottin et al. (2012).

\subsection{Test molecules}

In this "Mars" portion of the PROCESS experiment, the stability of the amino acids glycine and serine and the carboxylic acids phthalic acid and mellitic acid were tested in space under Mars-like surface UV radiation conditions. Glycine is one of the most abundant amino acids detected in meteorites and comets (Botta and Bada, 2002; Elsila et al., 2009), and its evolution under simulated martian conditions has already been studied in several laboratories (Ten Kate et al., 2005, 2006; Stalport et al., 2008). The occurrence of serine in meteorites is still uncertain, as it has not yet been detected above contamination levels (Brinton et al., 1998). It is expected to be present on Mars, however.

Phthalic and mellitic acids are aromatic carboxylic acids that have been proposed to be present at the surface of Mars (Benner et al., 2000). Laboratory studies have shown that the evolution of mellitic acid produces a radiotolerant organic compound identified as benzenehexacarboxylic acid-trianhydride $\left(\mathrm{C}_{12} \mathrm{O}_{9}\right)$ (Stalport et al., 2009). To study a possible photocatalytic interaction of phthalic acid with martian regolith (Shkrob et al., 2010), this acid was also exposed together with JSC Mars-1, a mineralogical analogue of martian soil that is composed of volcanic ashes collected in Hawaii and exhibits similarities to some bright areas of Mars (Allen et al., 1998).

\subsection{Flight experiment hardware}

For this "Mars" portion of the experiment PROCESS, closed exposure cells (12 mm diameter, $9.1 \mathrm{~mm}$ high) (Fig. 2) were used as described in Cottin et al. (2012). In brief, each cell was composed of two aluminum cylinders, which were placed in sample carriers that were situated one above the other. Samples in the upper carrier are exposed to UV radiation. Samples in the lower carrier are not exposed and function as dark controls. Each sample cylinder was covered 


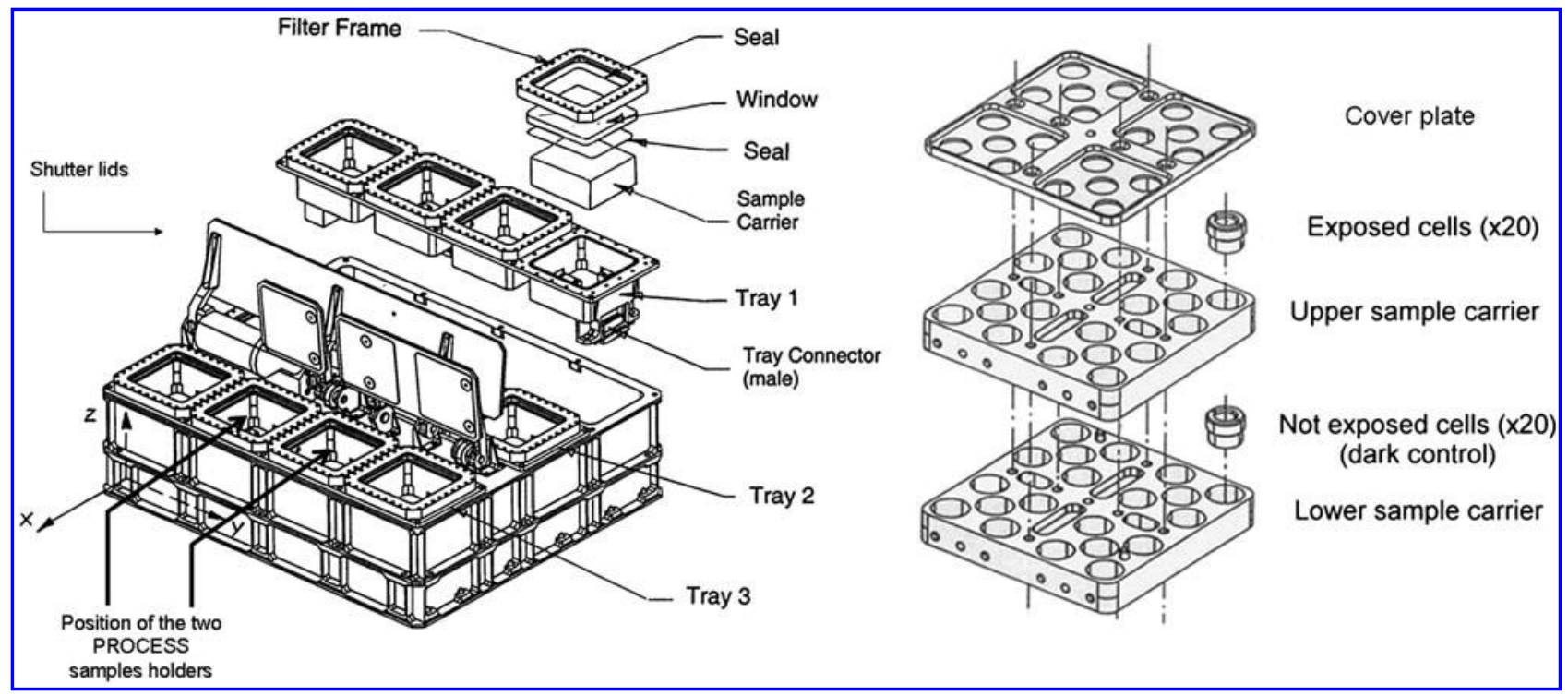

FIG. 1. Left: The EXPOSE facility $(480 \times 520 \times 327.5 \mathrm{~mm})$ is made of three experiment trays into which four square sample carriers $(77 \times 77 \times 26 \mathrm{~mm})$ are fitted (left). For PROCESS, two sample carriers were designed to receive 20 Sun-exposed cells and 20 not-exposed cells acting as flight dark control. Right: one of the 2 sample carriers. Pictures courtesy of Kayser-Threde $\mathrm{GmbH}$.

by a quartz window at both ends. After the top cylinder was loaded with one sample on the inner side of the quartz window, the two cylinders were screwed together in an argon atmosphere (1.5 bar). To minimize leaks of the closed exposure cell, it was sealed with a Viton O-ring and an external epoxy structural adhesive layer on the screw thread (2216 B/A, Scotch-Weld). The quartz windows (fused silica) were chosen because this material is transparent in the 190$400 \mathrm{~nm}$ wavelength range and efficiently absorbs photons below $170 \mathrm{~nm}$. The spectrum of the UV photons transmitted throughout such a window is close to that which reaches the surface of Mars (190-400 nm wavelength range) (Kuhn and Atreya, 1979; Cockell et al., 2000; Patel et al., 2002). On the EXPOSE-E facility, each cell in the upper carrier that was exposed to solar UV radiation was associated with another cell directly below it in the lower carrier that contained exactly the same content and was used as a flight dark control (Fig. 1). Some of the quartz windows delivered to us had optical defects, and preparation time for delivery to ESA did not allow for replacement of them. Those identified as defective were placed in the lower, unexposed carrier layers to minimize their impact on our results.

\subsection{Loading of the exposure cells}

The organic molecules were deposited as a homogeneous thin film on the quartz window ( $1 \mathrm{~mm}$ thick, $9 \mathrm{~mm}$ diameter) of each top cylinder by using a vacuum sublimation chamber (Guan et al., 2010). The films were a few hundred nanometers thick as measured by interferometry (Cottin et al., 2012). For

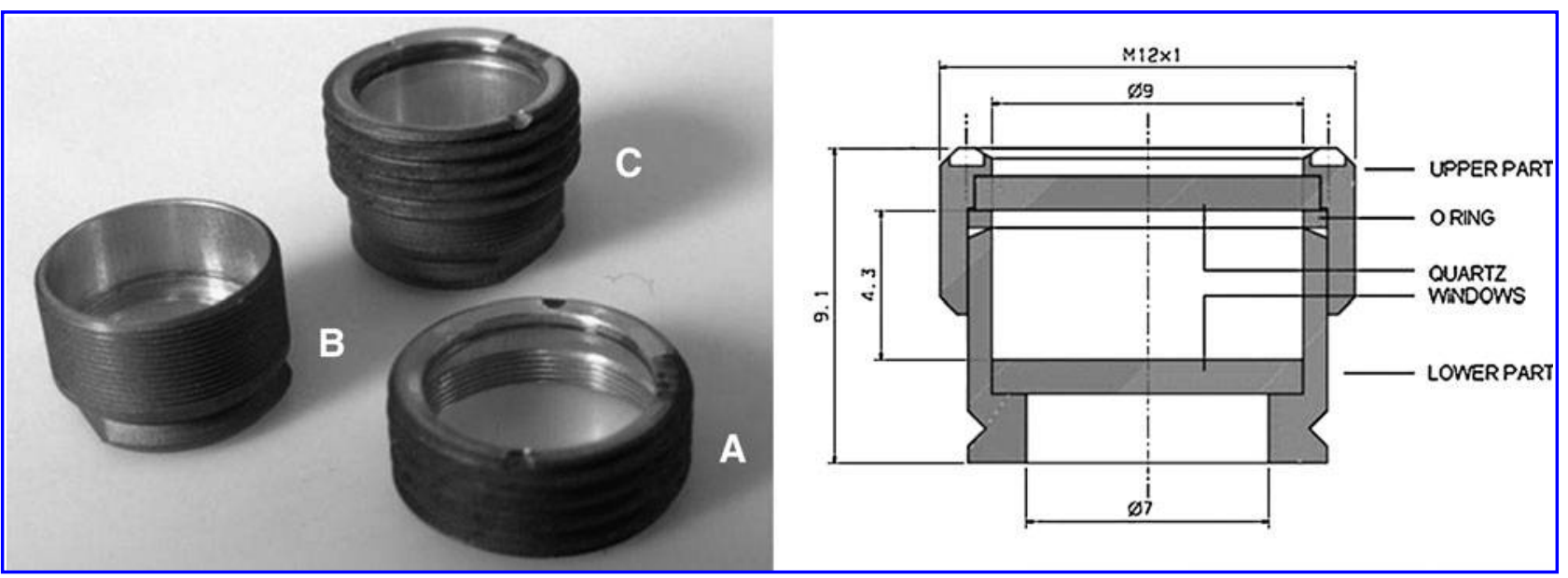

FIG. 2. Design of a closed cell. Two aluminum cylinders are screwed into each other: (A) Top; (B) bottom; (C) complete cell composed of a top (A) and a bottom (B). Two quartz windows are glued at both ends to allow the analysis of molecules inside the cell by spectroscopy. Sealing (relative to lab atmosphere or vacuum in space) is ensured by a Viton O-ring. Right picture courtesy of COMAT Aerospace. 


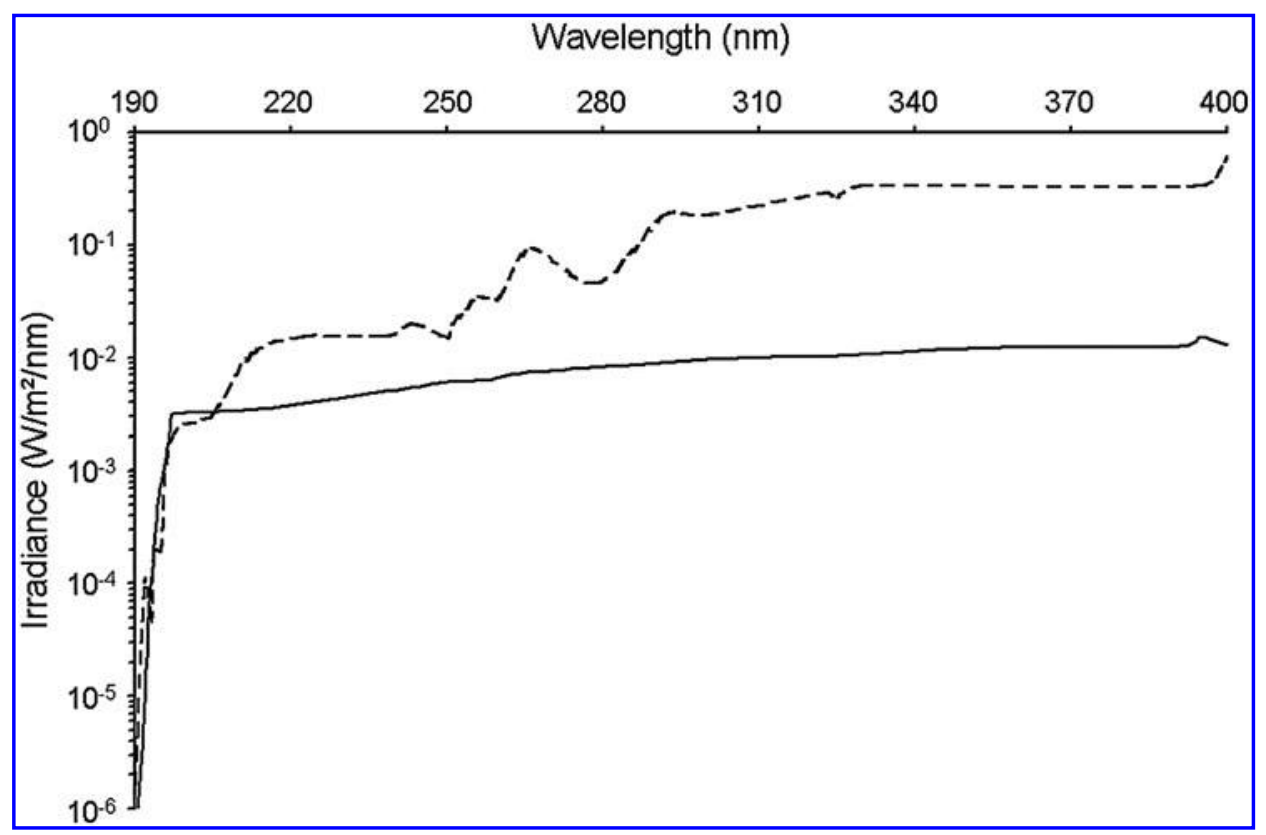

FIG. 3. UV spectrum of the xenon lamp (black line) compared to the solar UV spectrum on the martian surface predicted by Patel et al. (2002) at equatorial noontime (dotted line).

the phthalic acid-mineral combination, a stepwise approach was used. First, a mineral film was deposited on the quartz window as follows: the JSC Mars-1 soil was sieved, and the $<40 \mu \mathrm{m}$ fraction was collected and dispersed in ethanol; the suspension was deposited on the quartz window and then heated to $50^{\circ} \mathrm{C}$ to evaporate the ethanol. The mineral film was several hundred micrometers thick as measured by interferometry. The organic film was then deposited on the surface of the mineral phase by using the sublimation chamber. For each organic compound or compound-mineral combination, eight parallel samples (i.e., eight cells) were produced.

\subsection{Test parameters}

The eight samples were split into four pairs:

(i) Two "flight Sun-exposed" samples that were located in the upper sample carrier of the flight experiment (Fig. 1). After 1.5 years in space, these samples received a UV $(200-400 \mathrm{~nm})$ radiation fluence of $5.2 \times 10^{5} \mathrm{~kJ} /$ $\mathrm{m}^{2} \pm 15 \%$, as calculated from the ISS orbital parameters by the company RedShift (St Niklaas, Belgium) (Rabbow et al., 2012). These samples also experienced other space environmental conditions such as cosmic radiation of a total dose of 295.6 mGy (Berger et al., 2012; Dachev et al., 2012) and temperature fluctuations between $-21^{\circ} \mathrm{C}$ and $+61^{\circ} \mathrm{C}$ (Rabbow et al., 2012).

(ii) Two "flight dark control" samples that were located in the lower sample carrier of the flight experiment (Fig. 1). These samples experienced the same environmental conditions as those that were flight Sunexposed but no insolation.

(iii) Two "ground thermal cycling" samples that were kept in the Planetary and Space Simulation Facility at the German Aerospace Center (DLR), Cologne, Germany, under low pressure $\left(1.7 \times 10^{-8}\right.$ bar $)$ and submitted to thermal cycles, which reproduced the recorded flight temperature (Rabbow et al., 2012). (iv) Two "ground, constant temperature" samples that were kept at low pressure $\left(1.7 \times 10^{-8}\right.$ bar $)$ and constant temperature $\left(5^{\circ} \mathrm{C}\right)$ at the DLR facilities for the entire duration of the mission.

\subsection{Mars Organic Molecules Irradiation and Evolution facility}

To study in parallel the kinetics of evolution of organics under simulated martian conditions, a Mars simulation setup called the Mars Organic Molecules Irradiation and Evolution (MOMIE) facility was developed as described by Stalport et al. (2009) to reproduce the UV radiation climate at the martian surface. A UV source (Xenon arc lamp, LOTORIEL) was used that released photons in the 190-400 nm wavelength range (Fig. 3). For this study, the organic molecules were deposited by vacuum sublimation on $\mathrm{MgF}_{2}$ windows with transmission properties in the IR down to $1000 \mathrm{~cm}^{-1}$.

\subsection{Sample analyses}

The samples were analyzed before and after the mission by Fourier transform infrared (FTIR) spectroscopy (Perkin Elmer BXII spectrometer, resolution $4 \mathrm{~cm}^{-1}$, eight scans, spectral domain $4000-2000 \mathrm{~cm}^{-1}$ ) by direct transmission through the quartz window. The IR areas of the spectral feature's peaks before and after the mission were compared to measure the photolysis efficiency.

In the laboratory studies in which MOMIE was used, IR spectra were measured with the same instrument through the $\mathrm{MgF}_{2}$ windows (spectral domain $4000-1000 \mathrm{~cm}^{-1}$ ) as a function of photolysis time, and the evolution of the photoprocessing was parameterized according to

$$
\operatorname{Ln} \frac{[A]_{t}}{[A]_{0}}=-J \cdot t
$$




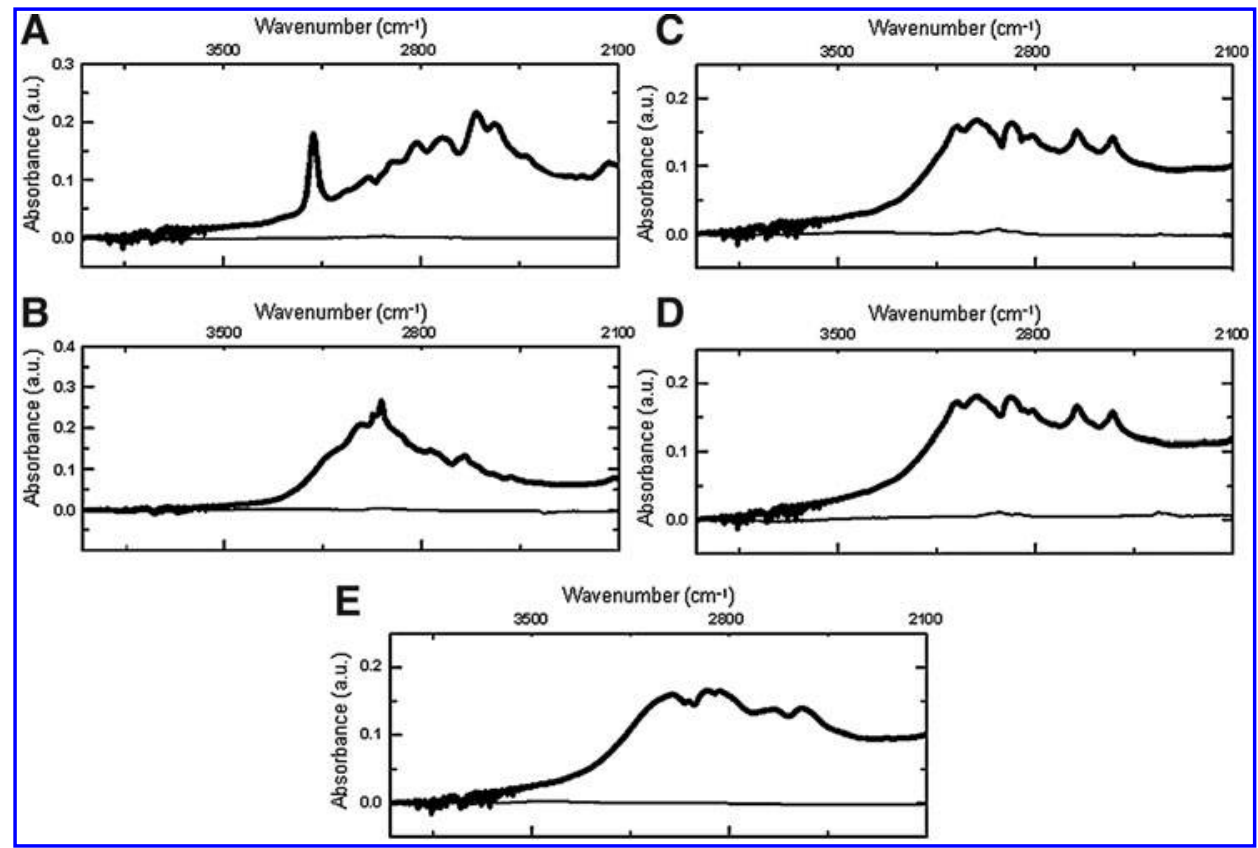

FIG. 4. IR spectra (in the $4000-2000 \mathrm{~cm}^{-1}$ wavelength range with a $4 \mathrm{~cm}^{-1}$ resolution) of a "flight Sun-exposed" sample before (bold) and after (fine) spaceflight; glycine (A); serine (B); phthalic acid (C); phthalic acid with JSC Mars-1 (D); mellitic acid (E) (a.u.=arbitrary units). with $[A]$ the abundance $A$ of the molecule, $t$ the irradiation time, and $J$ the photolysis rate ([time $]^{-1}$ ).

To study the gas phase after the mission, gas chromatography coupled to mass spectrometry (GC Varian CP 3800 and MS Varian Saturn 2200) was applied in addition to FTIR spectroscopy. First, each cell was immersed in dichloromethane $\left(\mathrm{CH}_{2} \mathrm{Cl}_{2}\right)$ for $75 \mathrm{~min}$ to degrade the epoxy adhesive. The samples were then opened in a specific airtight device called an "analytic cell" (Cottin et al., 2008, 2012). This analytical cell is interfaced to the GC-MS. Once a closed cell is opened inside the analytical cell, the gaseous samples are transferred to the GC injection loop and injected at $175^{\circ} \mathrm{C}$ in the splitless mode to maximize the quantity of gaseous species analyzed. The GC column was a Restek Q-plot capillary column $(30 \mathrm{~m} \times 0.25 \mathrm{~mm} \times 10 \mu \mathrm{m})$. This column is efficient for light hydrocarbons (C1-C12). The initial temperature of the column was $40^{\circ} \mathrm{C}$. After $4 \mathrm{~min}$ at $40^{\circ} \mathrm{C}$, the $\mathrm{GC}$ oven was ramped to $150^{\circ} \mathrm{C}$ at a rate of $10^{\circ} \mathrm{C} / \mathrm{min}$. The final temperature of the column was maintained at $150^{\circ} \mathrm{C}$ for 25 minutes. Pressure was set from 15 to 25 psi at $1.5 \mathrm{psi} / \mathrm{min}$. Products were measured with a quadrupole MS (14-200 m/z).

\section{Results}

\subsection{Solid phase: Fourier transform infrared analysis by transmission}

Fourier transform infrared spectra of the different test samples were taken at an interval of 4 years, either before the flight in July 2007 or after the mission and retrieval in July 2011. In Fig. 4, the IR spectra of the "flight Sun-exposed" samples are presented. After 4 years with 1.5 years in space, the spectral features of the initial sample had disappeared in all "flight Sun-exposed" samples, which indicates $0 \%$ recovery of the Sun-exposed samples after spaceflight (with the exception of one "flight Sun-exposed" glycine sample that showed $100 \%$ recovery, which means that this cell was not properly exposed to the Sun). In contrast, the percent re- covery of most samples that were not directly exposed to extraterrestrial solar UV radiation ("flight dark control," "ground thermal cycling," and "ground constant temperature") was $100 \%$ (data not shown). Exceptions were one "ground thermal cycling" glycine sample with $83 \%$ recovery and one "flight dark control" phthalic acid sample with $92 \%$ recovery. Both "flight dark control" samples of phthalic acid with JSC Mars-1 showed a reduced recovery (93\% and 74\%) as well as one "ground thermal cycling" sample of this organic-mineral combination (66\%). By comparing the results of the "flight Sun-exposed" samples with those of the "flight dark control" samples and both ground controls, the $0 \%$ recovery of the "flight Sun-exposed" samples can only be interpreted by photodegradation of these samples. The only interpretation of these results is that a UV (200-400 nm) radiation fluence of $5.2 \times 10^{5} \mathrm{~kJ} / \mathrm{m}^{2} \pm 15 \%$ completely photolyzed all test samples.

The laboratory simulations by use of MOMIE provided supportive information about the evolution kinetics of the organic molecules used in this study. The photolysis of the four organics investigated follows a first-order decay, Eq. 1 (Fig. 5). From these curves, the half-lives of glycine, serine, phthalic acid, and mellitic acid under Mars-like UV radiation were determined (Table 1).

\subsection{Gas phase: gas chromatography-mass spectrometry analysis}

The gaseous components of the flight cells and the ground control cells were analyzed by GC-MS after exposure, retrieval, and completion of the IR spectroscopy. For all cells, in addition to the expected argon, the gases $\mathrm{N}_{2}$ and $\mathrm{CH}_{2} \mathrm{Cl}_{2}$ were detected. In the gas phase of the "flight Sun-exposed" cells, the following hydrocarbons were measured: ethylene, ethane, propane, isobutane, and butane. These hydrocarbons were not found in the other cells, the "flight dark control," or the "ground control" cells, except trace amounts of ethane 


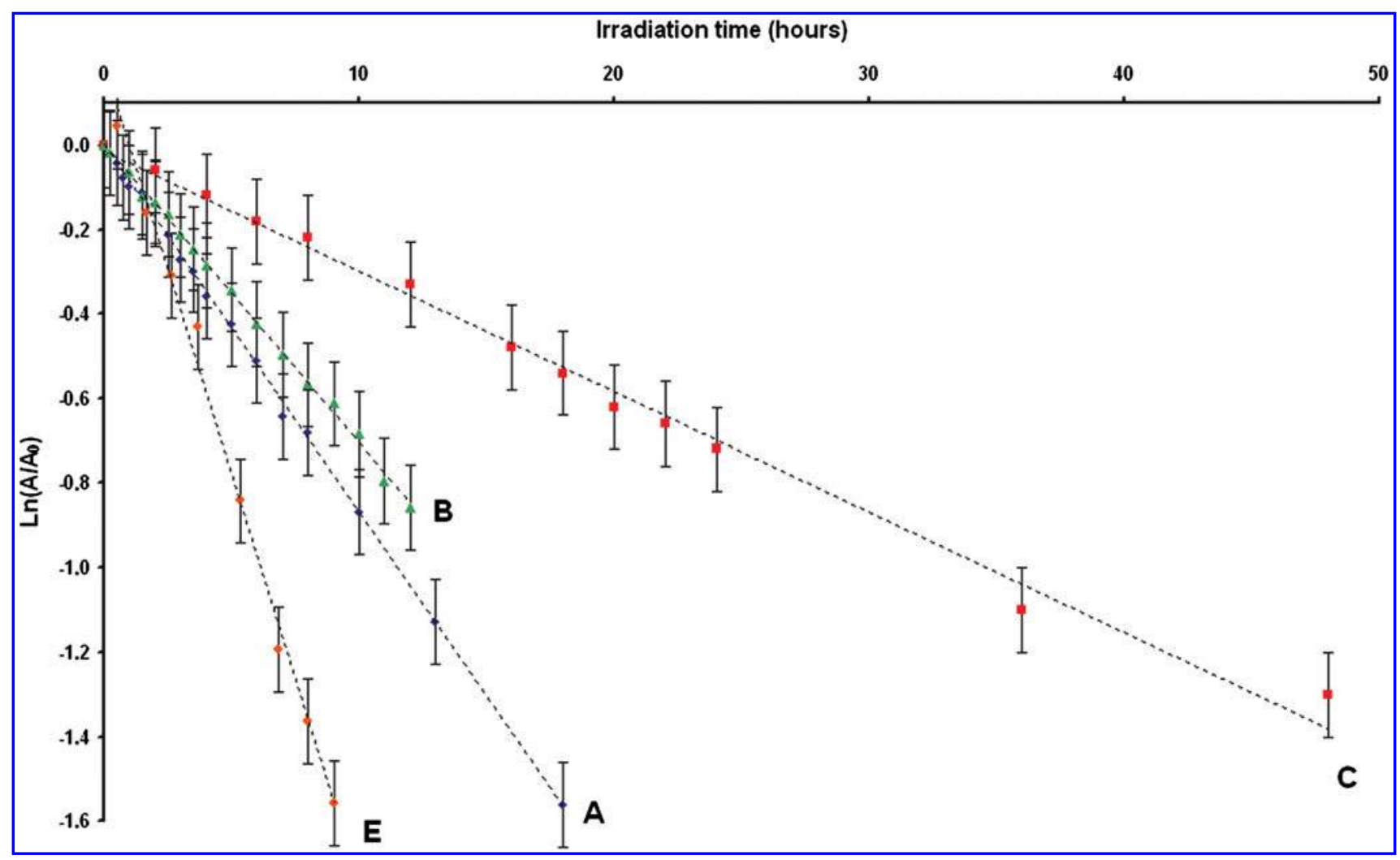

FIG. 5. Results of the photolysis rate of the organic targets from laboratory simulations (MOMIE). The natural logarithm of the normalized integrated absorbance $\left(\operatorname{Ln}\left(A / A_{0}\right)\right)$ is plotted against time for glycine $(\mathrm{A})$, serine $(\mathrm{B})$, phthalic acid $(\mathrm{C})$, mellitic acid (E). The linear correlation for mellitic acid has been obtained from one band. Color images available online at www .liebertonline.com/ast

that were detected in one "flight dark control" cell of glycine and one of serine.

The presence of $\mathrm{N}_{2}$ is the consequence of a leak during the injection of the samples into the GC-MS. The presence of $\mathrm{CH}_{2} \mathrm{Cl}_{2}$ (the solvent used to eliminate the epoxy adhesive) could be explained by its accumulation during the dissolution of the adhesive. The presence of $\mathrm{CO}_{2}$ could be explained by a leak during the injection into the GC-MS, but it could as well be a product of photodegradation.

Results are somewhat puzzling because the same hydrocarbons were detected from cells containing different organic molecules, and the detected molecules were not typical photodegradation products of amino acids. Their gaseous products should have been mostly $\mathrm{CO}_{2}$ and $\mathrm{HCN}$ (Ehrenfreund et al., 2001) and not the hydrocarbons detected in this

Table 1. Half-Lives of Glycine, Serine, and Phthalic ACID DETERMINEd FROM MOMIE EXPERIMENTS and Calculated for the Same Ranges of UV RADIATION (200-400 NM) OCCURRING IN LEO AND ON THe Surface of Mars

\begin{tabular}{|c|c|c|c|}
\hline Molecule & $\begin{array}{l}\text { Half-life } \\
\text { MOMIE } \\
\quad(h)\end{array}$ & $\begin{array}{l}\text { Calculated } \\
\text { half-life } \\
\text { in LEO }(h)\end{array}$ & $\begin{array}{c}\text { Calculated } \\
\text { half-life on the } \\
\text { surface of Mars }(h)\end{array}$ \\
\hline Glycine & $7.9 \pm 0.2$ & $17.3 \pm 0.5$ & $51.3 \pm 1.3$ \\
\hline Serine & $11.6 \pm 1.7$ & $25.4 \pm 3.7$ & $73.9 \pm 10.8$ \\
\hline Phthalic acid & $23.3 \pm 0.6$ & $51.0 \pm 1.3$ & $148.3 \pm 3.8$ \\
\hline
\end{tabular}

study. An explanation for the appearance of those hydrocarbons could be the photodegradation of the exposure cells themselves. Laboratory simulation tests conducted with the MOMIE experiment on the different cell components (coating, Viton O-rings) showed that UV radiation of an empty cell filled with O-rings produced the same gaseous compounds as measured in the "flight Sun-exposed" cells. Additional products were pentane, cyclopentane, cyclohexane, hexane, benzene, and toluene. Quantitative aspects cannot be addressed in the AMINO closed cell since they suffer from non-negligible leaking over such a long-duration experiment: from $5 \%$ to $100 \%$ between the filling and the postflight analysis. As the evolution of the leaking over time is not known, the amount of gaseous photoproducts cannot be precisely estimated from the gas chromatography measurements. Therefore, it is unknown whether the products detected in the gas phase of the "flight Sun-exposed" cells came from the degradation of the sample cells themselves or from a combination of such a contamination and actual photoproducts of the exposed organic samples. For future space experiments, a new generation of extra-tight cells has been developed, which should overcome these limitations.

\section{Discussion}

It was the aim of this study to determine the evolution of the amino acids glycine and serine and the carboxylic acids phthalic acid and mellitic acid under Mars-like surface UV radiation conditions with the filtered extraterrestrial solar electromagnetic spectrum. The FTIR results show that the 
direct exposure to simulated martian UV radiation for 1.5 years led to the total photodegradation of these organics. The presence of a mineral phase (phthalic acid with JSC Mars-1) did not change the results.

Due to the complete photodegradation of the exposed samples, a quantitative discussion about their photolysis kinetics is limited to the estimation of half-life upper limits and comparison with Mars simulation studies conducted in the laboratory (MOMIE). The integrated flux in the wavelength region $200-260 \mathrm{~nm}$ is for the Sun $3.2 \mathrm{~W} / \mathrm{m}^{2}$ at $1 \mathrm{AU}$ (Thuillier et al., 2004), whereas it is $7 \pm 2 \mathrm{~W} / \mathrm{m}^{2}$ for the solar simulator of MOMIE. The half-lives calculated from our laboratory experiments (Fig. 5) and rescaled to LEO conditions are $(17.3 \pm 0.5) \mathrm{h},(25.4 \pm 3.7) \mathrm{h}$, and $(51.0 \pm 1.3) \mathrm{h}$ for glycine, serine, and phthalic acid, respectively (Table 1). Half-life values for our samples exposed in LEO are $<220 \mathrm{~h}$ (upper limit considering a $<1 \%$ percent recovery and a firstorder decay, Eq. 1). The two sets of data are consistent and show that the laboratory simulations with the MOMIE setup provide credible values of kinetic parameters for the evolution of organic matter.

On Mars, the integrated flux in the $200-260 \mathrm{~nm}$ wavelength range has been given as $1.1 \pm 0.2 \mathrm{~W} / \mathrm{m}^{2}$ (Kuhn and Atreya, 1979; Cockell et al., 2000; Patel et al., 2002). Taking the MOMIE laboratory data (Fig. 5) and rescaling them to the martian conditions by cross calculation would give half-lives of glycine, serine, and phthalic acid on Mars of $(51.3 \pm 1.3) \mathrm{h}$, $(73.9 \pm 10.8) \mathrm{h}$, and $(148.3 \pm 3.8) \mathrm{h}$, respectively (Table 1$)$. From these values, it is possible to estimate the amount of these organic compounds in the martian regolith over time. The accumulation of such organic molecules would be due to the difference between their production/intake rates, which have been estimated to be between $2.4 \times 10^{7} \mathrm{~g} /$ year (Benner et al., 2000) and $2.4 \times 10^{8} \mathrm{~g} /$ year (Flynn, 1996), and the different pathways that may lead to their destruction, for example, by UV radiation. Assuming that the organic compounds were uniformly deposited at the surface of Mars and mixed with the regolith up to a depth of $1 \mathrm{~cm}$ [UV radiation is believed to penetrate only the first millimeter of the martian regolith, except in water ice, where the penetration would be several centimeters (Cockell and Raven, 2004)], and assuming only a few centimeters of the soil would be recycled by winds, then the maximal concentration of organics by weight would be less than $1 \mathrm{ppt}$ (with a maximal repartition on the surface of Mars of about $3 \times 10^{-7} \mathrm{~g} / \mathrm{m}^{2}$ and a density of the martian regolith of about $4 \mathrm{~g} / \mathrm{cm}^{3}$ ) (see also Stalport et al., 2010a). These data will be implemented into a future model focused on the concentration of organic matter at the surface of Mars according to the regolith depth, latitude, longitude, and seasons. The goal of this model will be to predict which compounds at what level could be detected on Mars by an in situ mission and what their origin (biotic versus abiotic) might be.

Degradation photoproducts are certainly released in the gas phase (and by extrapolation in the martian atmosphere), but they cannot be securely dissociated from contamination produced by the sample cells themselves. Therefore it is not possible to derive from our analyses reaction mechanisms of the photolysis of our organic samples in the martian environment. Such limitations due to our hardware have been investigated and will be taken into account for future LEO experiments.

\section{Conclusion}

Organic molecules of astrobiological interest were exposed to space conditions, and especially solar UV photons, during the PROCESS LEO experiment. Some of the samples were selected to study the behavior and stability of organic molecules (glycine, serine, phthalic acid, mellitic acid) that may be present on Mars. Our data show that the targeted molecules are not photostable because they were totally destroyed after the long-duration exposure to solar UV radiation, which was much longer than the duration of the UVolution experiment on board the ESA Biopan facility in 2007 (Stalport et al., 2010a). Laboratory experiments confirmed this result and provided crucial kinetic parameters to understand the preservation rates of organic matter at the surface of Mars.

Complementary experimental conditions, both in the laboratory and in LEO, are essential to understand the evolution of the samples. However, the experimental hardware for LEO experiments will have to be improved to eliminate the main limitations highlighted in this paper: (1) the contamination of the gas phase in the closed cells, (2) the low amount of data (limited amount of samples and replicates), (3) measurements only available before and after the experiment. Future experiments scheduled outside the International Space Station for late 2013 [such as Photochemistry on the Space Station (PSS) on the EXPOSE-R2 facility] will be prepared with a homogeneous and well-characterized new generation of closed cells, which will minimize leaks and contamination of results. Such new cells are currently under development and should be ready for the next experiments in which more space will be allocated such that more samples will be exposed (issue 2). A new next investigative step will be taken to address issue 3 with new generations of exposure instruments, which will include in situ diagnostics [O/OREO nanosatellite, OREOCube project for the ISS (Nicholson et al., 2011)] and the VITRINE project by the Centre National d'Études Spatiales.

\section{Acknowledgments}

This program has been selected by ESA in the frame of the AO Life and Physical Sciences and Applied Research Projects 2004. This study was supported by the French Centre National de la Recherche Scientifique (CNRS) and by the French Centre National d'Études Spatiales (CNES). It is based on observations with the PROCESS experiments on board EXPOSE-E. The authors would like to acknowledge the support of ESA (especially René Demets), CNES (especially Michel Viso for the human, financial, and technical support), French Program for Planetology (PNP), COMAT aerospace (Toulouse, France), and DLR Cologne (Elke Rabbow and Corinna Panitz). The authors would also like to acknowledge Gerda Horneck for helpful comments and help during the revision of the manuscript.

\section{Author Disclosure Statement}

No competing financial interests exist.

\section{Abbreviations}

DLR, Deutsches-Zentrum für Luft- und Raumfahrt e.V. (German Aerospace Center); FTIR, Fourier transform 
infrared; GC, gas chromatograph; ISS, International Space Station; LEO, low-Earth orbit; MOMIE, Mars Organic Molecules Irradiation and Evolution; MS, mass spectrometer.

\section{References}

Allen, C.C., Morris, R.V., Jager, K.M., Golden, D.C., Lindstrom, D.J., Lindstrom, M.M., and Lockwood, J.P. (1998) Martian regolith simulant JSC Mars-1 [abstract 1690]. In 29 ${ }^{\text {th }}$ Lunar and Planetary Institute Science Conference, Lunar and Planetary Institute, Houston.

Arvidson, R.E. (2000) Vision 2020: a proposed program of Mars exploration. In Concepts and Approaches for Mars Exploration, Lunar and Planetary Institute, Houston, p 6.

Benner, S.A., Devine, K.G., Matveeva, L.N. and Powell, D.H. (2000) The missing organic molecules on Mars. Proc Natl Acad Sci USA 97:2425-2430.

Berger, T., Hajek, M., Bilski, P., Körner, C., Vanhavere, F., and Reitz, G. (2012) Cosmic radiation exposure of biological test systems during the EXPOSE-E mission. Astrobiology 12:387-392.

Bibring, J.-P., Langevin, Y., Mustard, J.F., Poulet, F., Arvidson, R., Gendrin, A., Gondet, B., Mangold, N., Pinet, P., and Forget, F. (2006) Global mineralogical and aqueous Mars history derived from OMEGA/Mars Express data. Science 312:400-404.

Biemann, K. (1979) The implications and limitations of the findings of the Viking organic analysis experiment. I Mol Evol 14:65-70.

Botta, O. and Bada, J.L. (2002) Extraterrestrial organic compounds in meteorites. Surveys in Geophysics 23:411-467.

Brinton, K.L.F., Engrand, C., Glavin, D.P., Bada, J.L., and Maurette, M. (1998) A search for extraterrestrial amino acids in carbonaceous Antarctic micrometeorites. Orig Life Evol Biosph 28:413-424.

Cabane, M., Coll, P., Szopa, C., Israel, G., Raulin, F., Sternberg, R., Mahaffy, P., Person, A., Rodier, C., Navarro-Gonzalez, R., Niemann, H., Harpold, D., and Brinckerhoff, W. (2004) Did life exist on Mars? Search for organic and inorganic signatures, one of the goals for "SAM" (Sample Analysis at Mars). $\underline{A d v}$ Space Res 33:2240-2245.

Carter, J., Poulet, F., Bibring, J.-P., and Murchie, S. (2010) Detection of hydrated silicates in crustal outcrops in the northern plains of Mars. Science 328:1682-1686.

Cockell, C.S. and Raven, J.A. (2004) Zones of photosynthetic potential on Mars and the early Earth. Icarus 169:300-310.

Cockell, C.S., Catling, D.C., Davis, W.L., Snook, K., Kepner, R.L., Lee, P., and McKay, C.P. (2000) The ultraviolet environment of Mars: biological implications past, present, and future. Icarus 146:343-359.

Cottin, H., Gazeau, M.C., and Raulin, F. (1999) Cometary organic chemistry: a review from observations, numerical and experimental simulations. Planet Space Sci 47:1141-1162.

Cottin, H., Coll, P., Coscia, D., Fray, N., Guan, Y.Y., Macari, F., Raulin, F., Rivron, C., Stalport, F., Szopa, C., Chaput, D., Viso, M., Bertrand, M., Chabin, A., Thirkell, L., Westall, F., and Brack, A. (2008) Heterogeneous solid/gas chemistry of organic compounds related to comets, meteorites, Titan, and Mars: laboratory and in lower Earth orbit experiments. Adv Space Res 42:2019-2035.

Cottin, H., Guan, Y.Y., Noblet, A., Poch, O., Saiagh, K., Cloix, M., Macari, F., Jérome, M., Coll, P., Raulin, F., Stalport, F., Szopa, C., Bertrand, M., Chabin, A., Westall, F., Chaput, D., Demets, R., and Brack, A. (2012) The PROCESS experiment: an astrochemistry laboratory for solid and gaseous organic samples in low-Earth orbit. Astrobiology 12:412-425.

Dachev, T., Horneck, G., Häder, D.-P., Schuster, M., Richter, P., Lebert, M., and Demets, R. (2012) Time profile of cosmic ra- diation exposure during the EXPOSE-E mission: the R3DE instrument. Astrobiology 12:403-411.

Ehrenfreund, P., Glavin, D.P., Botta, O., Cooper, G., and Bada, J.L. (2001) Extraterrestrial amino acids in Orgueil and Ivuna: tracing the parent body of CI type carbonaceous chondrites. Proc Natl Acad Sci USA 98: 2138-2141.

Elsila, J.E., Glavin, D.P., and Dworkin, J.P. (2009) Cometary glycine detected in samples returned by Stardust. Meteorit Planet Sci 44:1323-1330.

Flynn, G.J. (1996) The delivery of organic matter from asteroids and comets to the early surface of Mars. Earth Moon Planets 72:469-474.

Gontareva, N.B. (2005) Photochemical stability of biomolecules in the experiments modelling martian surface conditions. International Journal of Astrobiology 4:93-96.

Guan, Y.Y., Fray, N., Coll, P., Macari, F.D.R., Chaput, D., Raulin, F.O., and Cottin, H. (2010) UVolution: compared photochemistry of prebiotic organic compounds in low Earth orbit and in the laboratory. Planet Space Sci 58:1327-1346.

Hoehler, T.M. and Westall, F. (2010) Mars Exploration Program Analysis Group Goal One: determine if life ever arose on Mars. Astrobiology 10:859-867.

Kuhn, W.R. and Atreya, S.K. (1979) Solar radiation incident on the martian surface. L Mol Evol 14:57-64.

Mangold, N., Quantin, C., Ansan, V., Delacourt, C., and Allemand, P. (2004) Evidence for Precipitation on Mars from dendritic valleys in the Valles Marineris Area. Science 305: 78-81.

Morrison, D. (2001) The NASA Astrobiology Program. Astrobiology 1:3-13.

Navarro-González, R., Navarro, K.F., Rosa, J.D.L., Iniguez, E., Molina, P., Miranda, L.D., Morales, P., Cienfuegos, E., Coll, P., Raulin, F., Amils, R., and McKay, C.P. (2006) The limitations on organic detection in Mars-like soils by thermal volatilization-gas chromatography-MS and their implications for the Viking results. Proc Natl Acad Sci USA 103:16089-16094.

Navarro-González, R., Vargas, E., de la Rosa, J., Raga, A.C., and McKay, C.P. (2010) Reanalysis of the Viking results suggests perchlorate and organics at midlatitudes on Mars. J Geophys Res 115, doi:10.1029/2010JE003599.

Nicholson, W.L., Ricco, A.J., Agasid, E., Beasley, C., DiazAguado, M., Ehrenfreund, P., Friedericks, C., Ghassemieh, S., Henschke, M., Hines, J.W., Kitts, C., Luzzi, E., Ly, D., Mai, N., Mancinelli, R., McIntyre, M., Minelli, G., Neumann, M., Parra, M., Piccini, M., Rasay, R.M., Ricks, R., Santos, O., Schooley, A., Squires, D., Timucin, L., Yost, B., and Young, A. (2011) The O/ OREOS mission: first science data from the Space Environment Survivability of Living Organisms (SESLO) payload. Astrobiology 11:951-958.

Patel, M.R., Zarnecki, J.C., and Catling, D.C. (2002) Ultraviolet radiation on the surface of Mars and the Beagle 2 UV sensor. Planet Space Sci 50:915-927.

Poulet, F., Bibring, J.-P., Mustard, J.F., Gendrin, A., Mangold, N., Langevin, Y., Arvidson, R.E., Gondet, B., and Gomez, C. (2005) Phyllosilicates on Mars and implications for early martian climate. Nature 438:623-627.

Rabbow, E., Rettberg, P., Barczyk, S., Bohmeier, M., Parpart, A., Panitz, C., Horneck, G., von Heise-Rotenburg, R., Hoppenbrouwers, T., Willnecker, R., Baglioni, P., Demets, R., Dettmann, J., and Reitz, G. (2012) EXPOSE-E: an ESA astrobiology mission 1.5 years in space. Astrobiology 12:374-386.

Schmitt-Kopplin, P., Gabelica, Z., Gougeon, R.G.D., Fekete, A., Kanawati, B., Harir, M., Gebefuegi, I., Eckel, G., and Hertkorn, N. (2010) High molecular diversity of extraterrestrial organic 
matter in Murchison meteorite revealed 40 years after its fall. Proc Natl Acad Sci USA 107:2763-2768.

Shkrob, I.A., Chemerisov, S.D., and Marin, T.W. (2010) Photocatalytic decomposition of carboxylated molecules on light-exposed martian regolith and its relation to methane production on Mars. Astrobiology 10:425-436.

Squyres, S.W., Arvidson, R.E., Bell, J.F., Brückner, J., Cabrol, N.A., Calvin, W., Carr, M.H., Christensen, P.R., Clark, B.C., Crumpler, L., Des Marais, D.J., d'Uston, C., Economou, T., Farmer, J., Farrand, W., Folkner, W., Golombek, M., Gorevan, S., Grant, J.A., Greeley, R., Grotzinger, J., Haskin, L., Herkenhoff, K.E., Hviid, S., Johnson, J., Klingelhöfer, G., Knoll, A.H., Landis, G., Lemmon, M., Li, R., Madsen, M.B., Malin, M.C., McLennan, S.M., McSween, H.Y., Ming, D.W., Moersch, J., Morris, R.V., Parker, T., Rice, J.W., Richter, L., Rieder, R., Sims, M., Smith, M., Smith, P., Soderblom, L.A., Sullivan, R., Wänke, H., Wdowiak, T., Wolff, M., and Yen, A. (2004) The Opportunity Rover's Athena Science Investigation at Meridiani Planum, Mars. Science 306:1698-1703.

Stalport, F., Coll, P., Szopa, C., and Raulin, F. (2008) Search for organic molecules at the Mars surface: The "Martian Organic Material Irradiation and Evolution" (MOMIE) project. Adv Space Res 42:2014-2018.

Stalport, F., Coll, P., Szopa, C., Cottin, H., and Raulin, F. (2009) Investigating the photostability of carboxylic acids exposed to Mars surface ultraviolet radiation conditions. Astrobiology 9:543-549.

Stalport, F., Guan, Y.Y., Coll, P., Szopa, C., Macari, F., Raulin, F., Chaput, D., and Cottin, H. (2010a) UVolution, a photochemistry experiment in low-Earth orbit: investigation of the photostability of carboxylic acids exposed to Mars surface UV radiation conditions. Astrobiology 10:449-461.

Stalport, F., Guan, Y.Y., Audrey, N., Coll, P., Szopa, C., Macari, F., Person, A., Chaput, D., Raulin, F., and Cottin, H. (2010b)
UVolution, a photochemistry experiment in low earth orbit: investigation of the photostability of carbonates exposed to martian-like UV radiation conditions. Planet Space Sci 58:16171624.

Stoker, C.R. and Bullock, M.A. (1997) Organic degradation under simulated martian conditions. I Geophys Res 102:1088110888.

Ten Kate, I.L., Garry, J.R.C., Peeters, Z., Quinn, R., Foing, B., and Ehrenfreund, P. (2005) Amino acid photostability on the martian surface. Meteorit Planet Sci 40:1185-1193.

Ten Kate, I.L., Garry, J.R.C., Peeters, Z., Foing, B., and Ehrenfreund, P. (2006) The effects of martian near surface conditions on the photochemistry of amino acids. Planet Space Sci 54:296-302.

Thuillier, G., Floyd, L., Woods, T.N., Cebula, R., Hilsenrath, E., Hersé, M., and Labs, D. (2004) Solar irradiance reference spectra for two solar active levels. Adv Space Res 34:256-261.

Address correspondence to: Fabien Stalport

LISA

Universités Paris Est Créteil and Paris Diderot

CNRS

Institut Pierre Simon Laplace

UMR 7583

61 avenue du Général de Gaulle

94010 Créteil cedex

France

E-mail: fabien.stalport@lisa.u-pec.fr

Submitted 21 October 2011

Accepted 7 May 2012 


\section{This article has been cited by:}

1. Hervé Cottin, Yuan Yong Guan, Audrey Noblet, Olivier Poch, Kafila Saiagh, Mégane Cloix , Frédérique Macari , Murielle Jérome , Patrice Coll , François Raulin , Fabien Stalport, Cyril Szopa, Marylène Bertrand, Annie Chabin, Frances Westall , Didier Chaput, René Demets , André Brack . 2012. The PROCESS Experiment: An Astrochemistry Laboratory for Solid and Gaseous Organic Samples in Low-Earth Orbit. Astrobiology 12:5, 412-425. [Abstract] [Full Text HTML] [Full Text PDF] [Full Text PDF with Links]

2. Elke Rabbow, Petra Rettberg, Simon Barczyk, Maria Bohmeier, André Parpart, Corinna Panitz, Gerda Horneck , Ralf von Heise-Rotenburg, Tom Hoppenbrouwers, Rainer Willnecker, Pietro Baglioni , René Demets , Jan Dettmann , Guenther Reitz . 2012. EXPOSE-E: An ESA Astrobiology Mission 1.5 Years in Space. Astrobiology 12:5, 374-386. [Abstract] [Full Text HTML] [Full Text PDF] [Full Text PDF with Links] 